\title{
Adequate antenatal care and ethnicity affect preterm birth in pregnant women living in the tropical rainforest of Suriname
}

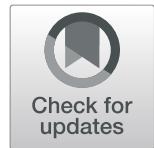

\author{
G. K. Baldewsingh ${ }^{1,2^{*}}$ D, B. C. Jubitana ${ }^{1}$, E. D. van Eer ${ }^{1}$, A. Shankar ${ }^{3}$, A. D. Hindori-Mohangoo ${ }^{3,4}$, H. H. Covert ${ }^{3}$, L. Shi ${ }^{3}$, \\ M. Y. Lichtveld ${ }^{3,5}$ and C. W. R. Zijlmans ${ }^{2,3,5}$
}

\begin{abstract}
Background: Adequate antenatal care (ANC) services are key for early identification of pregnancy related risk factors and maintaining women's health during pregnancy. This study aimed to assess the influence of ANC provided by the Medical Mission Primary Health Care Suriname (MMPHCS) and of ethnicity on adverse birth outcomes in Tribal and Indigenous women living in Suriname's remote tropical rainforest interior.
\end{abstract}

Method: From April 2017 to December 2018 eligible Tribal and Indigenous women with a singleton pregnancy that received ANC from MMPHCS were included in the study. Data on low birth weight (LBW $<2500 \mathrm{~g}$ ), preterm birth (PTB $<37$ weeks), low Apgar score ( $<7$ at 5 min), parity ( $\leq 1$ vs. $>1)$ and antenatal visits utilization ( $\geq 8$ vs. $<8$ ) in 15 interior communities were retrospectively analyzed using descriptive statistics, crosstabs and Fisher's exact tests.

Results: A total of 204 women were included, 100 (49\%) were Tribal, mean age was $26 \pm 7.2$ years and 126 women (62\%) had 8 or more ANC visits. One participant had a miscarriage; 22\% had adverse birth outcomes: 16 (7.9\%) LBW and 30 (14.8\%) PTB; 7 women had a child with both PTB and LBW; 5 women had stillbirths. None of the newborns had low Apgar scores. Maternal age, ethnicity, ANC and parity were associated with PTB $\left(x^{2}=8,75, p=0.003, x^{2}=4\right.$, 97, $p=0.025, X^{2}=17,45, p<0.001, X^{2}=11,93, p<0.001$ respectively).

Conclusion: Despite an almost 100\% study adherence over one fifth of women that received ANC in the interior of Suriname had adverse birth outcomes, in particular PTB and LBW. Younger nulliparous Indigenous women with less than the recommended 8 ANC visits had a higher risk for PTB. The rate of adverse birth outcomes highlights the need for further research to better assess factors influencing perinatal outcomes and to put strategies in place to improve perinatal outcomes. Exposure assessment of this sub-cohort and neurodevelopment testing of their children is ongoing and will further inform on potential adverse health effects associated with environmental exposures including heavy metals such as mercury and lead.

Keywords: Antenatal care utilization and content, Birth outcomes, Indigenous, Tribal, Suriname

\footnotetext{
* Correspondence: gbaldewsingh@medischezending.sr

'Medical Mission Primary Health Care Suriname, Paramaribo, Suriname

${ }^{2}$ Faculty of Medical Sciences, Anton de Kom University of Suriname, Paramaribo, Suriname

Full list of author information is available at the end of the article
}

(C) The Author(s). 2020 Open Access This article is licensed under a Creative Commons Attribution 4.0 International License, which permits use, sharing, adaptation, distribution and reproduction in any medium or format, as long as you give appropriate credit to the original author(s) and the source, provide a link to the Creative Commons licence, and indicate if changes were made. The images or other third party material in this article are included in the article's Creative Commons licence, unless indicated otherwise in a credit line to the material. If material is not included in the article's Creative Commons licence and your intended use is not permitted by statutory regulation or exceeds the permitted use, you will need to obtain permission directly from the copyright holder. To view a copy of this licence, visit http://creativecommons.org/licenses/by/4.0/. The Creative Commons Public Domain Dedication waiver (http://creativecommons.org/publicdomain/zero/1.0/) applies to the data made available in this article, unless otherwise stated in a credit line to the data. 


\section{Background}

Antenatal care (ANC) services provided by healthcare professionals are key for early identification of pregnancy related risk factors and maintaining women's health during pregnancy. During 2010-2015, ANC coverage, defined as the percentage of pregnant women aged 1549 years who attended at least one ANC visit with a skilled health care provider, was approximately $85 \%$ globally and $77 \%$ in the least developed countries [1]. According to the WHO, an estimated 303,000 women died from pregnancy-related causes worldwide in 2015, while 2.7 million babies died during the first 28 days of life and 2.6 million were stillborn. Both improvement of quality of healthcare during pregnancy and childbirth and increasing the number of ANC visits $(\geq 8)$ could prevent many of these deaths $[1,2]$. In addition, improved prenatal care is also associated with greater maternal satisfaction [3]. Adequate ANC is therefore considered to be effective in reducing complications during pregnancy and delivery [4]. In 2018, the worldwide neonatal mortality rate (NMR) was 18 deaths per 1000 live births, in Latin America and the Caribbean 9/1000 live births. Suriname had the 3rd highest NMR in South America with 10/1000 live births [5].

Suriname is an upper middle income country in northeast South America with an estimated population of 575,991 [6]; $10 \%$ of the population lives in the remote tropical rainforest interior. Of the interior population, 83\% are Tribal (descendants of runaway African slaves) and $17 \%$ are Indigenous (Amerindians). These populations live in relatively small communities with their own cultural beliefs and many speak their own native language. The Medical Mission Primary Health Care Suriname (MMPHCS) is the primary health care provider for the interior population. Annual births in Suriname are estimated at 10,000 [7]. Approximately 93\% of all deliveries across the country are facility-based, either in the hospital or at a primary health care clinic [8]. MMPHCS provides ANC as part of its maternal and childcare portfolio and follows the WHO's recommendations for effective ANC in order to improve maternal and neonatal health outcomes. So far, the quality and effectiveness of ANC provided by MMPHCS for the interior population in Suriname, measured by outcomes such as adverse birth outcomes, has not yet been assessed. In addition, potential differences in birth outcomes related to ANC between Tribal and Indigenous communities with their unique assets, health and cultural traditions were never studied.

This study aimed to evaluate prenatal care, as measured by the quality and number of ANC services provided by MMPHCS on birth outcomes among pregnant women in Suriname's interior. We hypothesized that adequate prenatal care would have a positively influence on birth outcomes. Also, we assessed potential differences in birth outcomes between Tribal and Indigenous communities.

\section{Methods \\ Antenatal care services}

In this prospective cohort study a review of the ANC services was conducted to identify the quality of ANC provided by the MMPHCS. ANC was defined as the total package of care that pregnant women receive from an organized health facility. The three components considered for quality of ANC were: 1 ) the timing of first ANC visit 2) the number of ANC visits and 3) health services provided during each visit. According to the WHO these three components ensure timely risk identification, prevention and management of pregnancyrelated or current diseases and health education and health promotion.

MMPHCS provides primary healthcare services 24/7, including emergency care, maternal and childcare, family planning, management of communicable and noncommunicable diseases, school health program, dental care, home visits to elderly and health education and promotion activities. The ANC guidelines include: monitoring of weight, blood pressure and blood sugar, deworming, toxoid immunization, malaria testing and treatment, counseling and testing for Human Immunodeficiency Virus, Syphilis and Hepatitis B, blood and urine testing, iron and folic acid supplementation, uncomplicated delivery at MMPHCS healthcare facility, early identification and referral of high risk pregnancies, health education regarding pregnancy and breastfeeding, and home visits. Adequate ANC services was defined as at least eight ANC contacts with the MMPHCS healthcare provider starting from the first trimester of pregnancy.

There are no specialized neonatal care facilities in the interior. Newborns that need special care are immediately transported to the hospitals in the city. Preferably pregnant women in premature labor are referred in time to the capital city. Reasons for referral to the gynecologist would be risk factors such as grand multiparous women, adolescent nulliparous, hypertension, obesity, anemia or previous $\mathrm{C}$-sections.

\section{Study population}

The study population is a subset of the overall Caribbean Consortium of Environmental and Occupational Health (CCREOH) environmental epidemiologic cohort study that examines the effects of chemical and non-chemical stressors on birth outcomes and pediatric neurodevelopment in mother/child dyads in Suriname. To date 1069 mothers and their infants are included [9]. 
Women aged 16 years and older with a singleton pregnancy who had registered at one of 15 randomly selected MMPHCS health centers were eligible to enroll in the study (Fig. 1). The interior population consists only of Tribal and Indigenous communities. These are mostly situated far from the capital in remote areas near the large rivers in the interior only reachable by air or water and engage in subsistence livelihood based on local fishing, hunting and growing manioc and other root vegetables. These two communities live in their own regions and hardly interact with each other. We compared those two groups as they are culturally distinct and are of different race and ethnicity.

\section{Data analysis plan}

Descriptive statistics were calculated for the study population and presented as means, standard deviations (SD) for continuous variables and numbers/proportions for categorical variables including age, ethnicity, parity, number of antenatal visits, preterm birth, birth weight, and Apgar score at $5 \mathrm{~min}$.

Categorical variables were assessed using crosstabs. Socio-demographic variables were re-coded for the logistic regression models as follows: age at delivery as $<20$ and $\geq 35$ vs. $20-34$ years; parity as nulliparous or one previous live birth vs. more than one previous live birth; and ethnic group as Tribal vs. Indigenous.

The dependent variables preterm birth (PTB), low birth weight (LBW) and Apgar score (AS) were recoded as binominal variables and defined as follows: PTB as < 37 vs. $\geq 37$ weeks, LBW as $<2500$ vs. $\geq 2500$ g, and Apgar score as $<7$ vs. $\geq 7$ at $5 \mathrm{~min}$. Gestational age was calculated using the last menstrual period (LMP). Newborns $<28$ weeks were excluded from the analyses. Crosstabs were used to explore associations between each of the outcome variables. Differences in proportions between variables were tested with the Pearson's chi-squared test and if assumptions were not met, Fisher's exact test was used. Multiple logistic regression was used to develop predictive models for the outcome variables. Variables included in the logistic model were based on the results of the bivariate associations. All analyses were conducted using IBM SPSS version 20 and EPI INFO ${ }^{\mathrm{ma}}$ version 7.2.2.6.

\section{Ethics}

Written informed consents in the native languages Saramaccan and Trio were obtained. Ethical approval was granted by the Institutional Review Board of the Government of Suriname (VG 023-14) and the Tulane University Institutional Review Board. Participants were enrolled from April 2017 through December 2018.

\section{Results}

Of the 206 eligible pregnant women, 203 were ultimately included in the study (Fig. 2). One participant delivered twins and was therefore excluded and one participant from a Tribal community was lost to follow up. 100 (49\%) women were from a Tribal community and 104 (51\%) were Indigenous. $90 \%$ of women returned for follow up visits until the end of their pregnancy. $97 \%$ of women had a live birth, $22 \%$ had adverse birth outcomes (data not shown). 7 women delivered before 33 weeks gestation, their newborns were excluded from the study as this was one of the exclusion criteria.

The overall mean age (SD) of the participants was 26 years (7.2); $46(22.5 \%)$ were $<20$ years of age of which $16(34.8 \%)$ were from a Tribal community and 30 (65.2\%) were Indigenous (Table 1). 50\% of the Indigenous population in the age group of $<20$ years had less than eight ANC visits.

116 (72\%) participants' first ANC visit was within the first 4 months of pregnancy. 201 (99\%) deliveries were facility-based with a skilled birth attendant present; two women delivered at home. 126 (61.8\%) women had eight or more ANC visits, data on ANC visits were missing for $17(8.3 \%)$ of cases. $60 \%$ of the Indigenous women had less than 8 ANC visits compared to $48 \%$ of the Tribal women (Table 1).

$77(38 \%)$ of the women delivered at one of the health facilities in the interior, $127(62 \%)$ were referred to the hospital for delivery. 76 (59\%) of the referred participants were of the Tribal and $52(41 \%)$ of the Indigenous community. Reasons for referral for Tribal and Indigenous women were respectively: teenage pregnancy and nulliparity $11(14.5 \%)$ vs. 16 (30.8\%), grand multiparity 25 (37.9\%) vs. 7 (11.5\%) and other (obstructed labor, previous C-section, anemia, hypertension, obesitas) 40 (31.2\%) vs. 29 (22.7\%).

\section{Maternal outcomes}

$10(4.9 \%)$ participants from the Tribal community had pregnancy-induced hypertension of which 3 women developed pre-eclampsia. One participant in the Tribal community had diabetes gravidarum. None of the Indigenous women had either hypertension or diabetes. 187 (92\%) of the participants had vaginal delivery. A total of 198 (97\%) women had live births, five participants had a stillbirth (3 Tribal and 2 Indigenous), and one Tribal participant had a miscarriage.

The distribution of birth outcomes is presented in Table 2. Of all births, 30 (14.8\%) were PTB and 16 (7.9\%) had LBW. 7 women had a child with both PTB and LBW. 27.9\% (29/104) of the Indigenous study population had either PTB or LBW, while 17\% (17/99) of the Tribal had either PTB or LBW. 26 (56.5\%) of women with adverse birth outcomes were referred to the capital. 


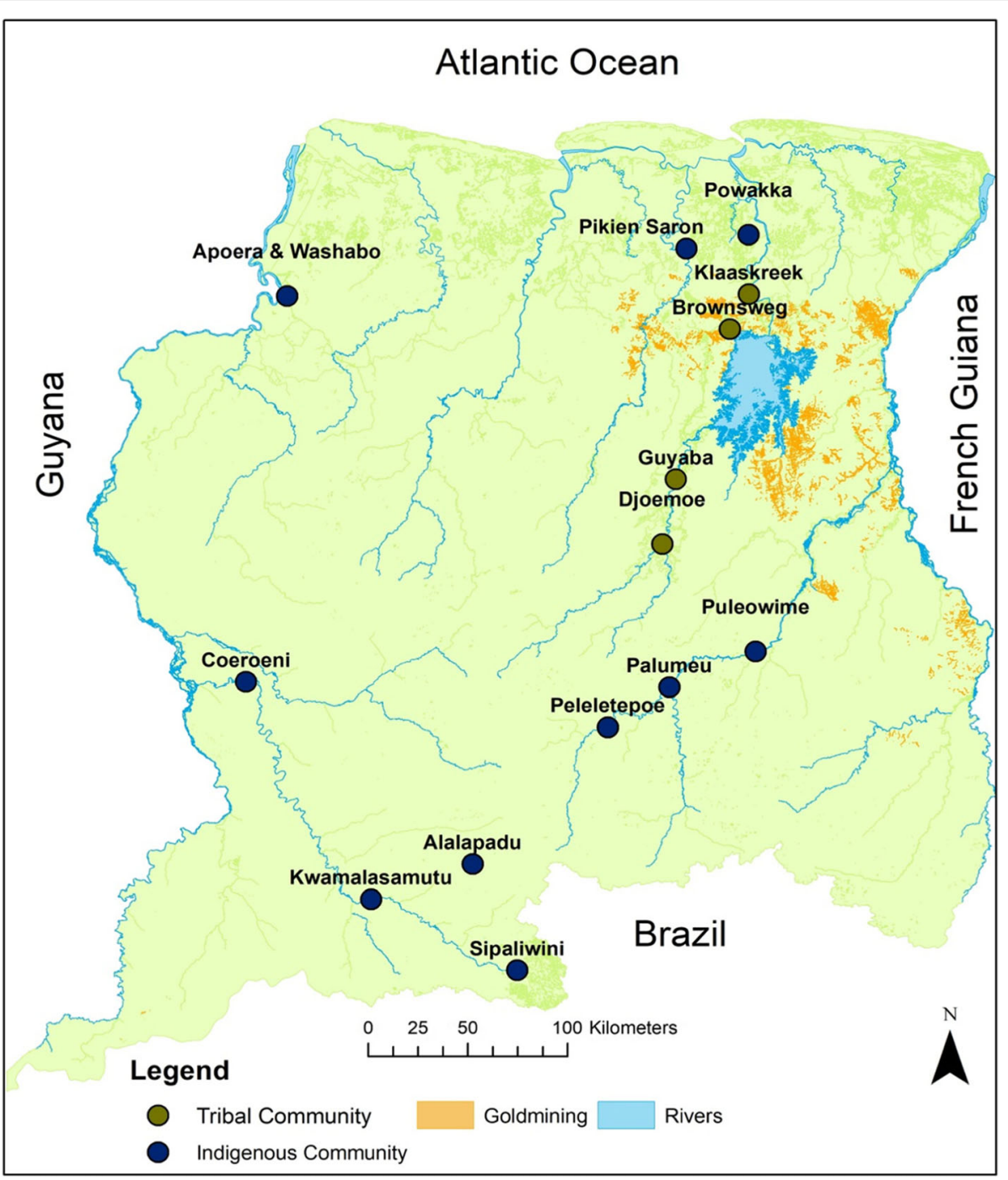

Fig. 1 Recruitment areas in the Medical Mission Primary Health Care Suriname regions. Map created in ArcGis 10.1 software; GIS data retrieved from the open source portal www.gonini.org

There were no differences in PTB and LBW between referred and non-referred Tribal or Indigenous women. None of the newborns had an Apgar score $<7$ at $5 \mathrm{~min}$. An Apgar score was missing in 2\% (4/198) of the cases.

Maternal characteristics associated with LBW and PTB are presented in Table 3. No significant association was observed for age, ethnicity, ANC, and parity and LBW. Age, ethnicity, ANC and parity were associated with PTB, Pearson's chi-squared $x^{2}=11,83, p=0.005$, $X^{2}=4,97, \quad p=0.026, \quad X^{2}=17,45, \quad p<0.001, \quad X^{2}=11,47$, $p<0.001$ respectively. Multivariate analysis for place of birth as dependent and PTB, age, ANC, ethnicity, parity and $\mathrm{BW}$ as independent variable showed an association for ANC $(<8$ visits, $p<0.005)$ and ethnicity (Tribal, $p<0.005)$ for women who were referred to the hospital.

\section{Discussion}

We aimed to assess the utilization of antenatal care and its effect on birth outcomes, specifically PTB and LBW, and potential differences between Tribal and Indigenous pregnant women from Suriname's interior receiving ANC services from the MMPHCS. ANC adherence of the women enrolled in the study was appropriately high: nine out of ten women returned for follow up visits until the end of their pregnancy. $97 \%$ of women had a live birth, $62 \%$ were referred to the hospital, $22 \%$ had adverse birth outcomes of which $56.5 \%$ in the referral group. PTB was positively associated with less number of ANC visits, young age, Indigenous ethnicity, and nulliparity. LBW was not associated with any of these risk factors.

Despite the high ANC adherence, the 14.8\% PTB rate observed in this study population was higher compared 


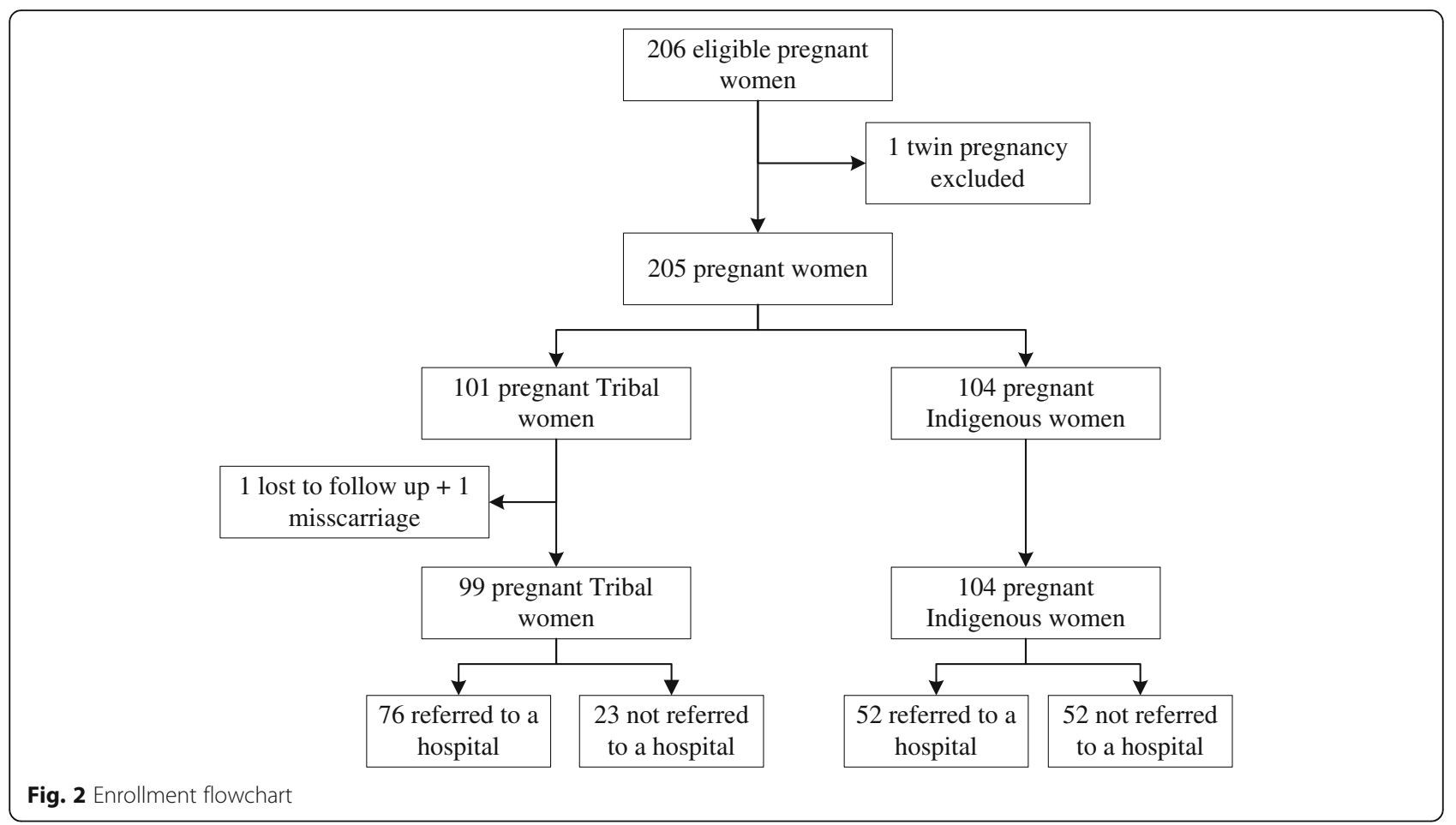

to the rate of $12 \%$ in lower income countries and the $9 \%$ rate in high-income countries [10] and was comparable to the country estimate (14\%; Verscheuren, et al., Childbirth outcomes and Ethnic disparities in Suriname, accepted for publication April 2020). PTB rate may be influenced by several factors such as gestational age determination, maternal age, ethnicity, parity and ANC utilization. In our study, PTB was determined with LMP based on the participant's recall. This can be influenced by irregular menses, misinterpretation of vaginal bleeding in early pregnancy as a menstrual cycle, and individual variation in menstruation length cycle. A comparable Brazilian study suggested that the association between young age and PTB may have a biological basis, or that is was caused because of errors in estimation of LMP by young mothers [11]. Hence our approach could have

Table 1 Characteristics pregnant women receiving antenatal care in the interior of Suriname $(N=204)$

\begin{tabular}{|c|c|c|c|c|c|c|c|c|c|}
\hline $\mathrm{t} 1.1$ & Variable & $N=204$ & (\%) & Mean \pm SD & N (\%) & Mean \pm SD & N (\%) & Mean \pm SD & $p$-value \\
\hline $\mathrm{t} 1.2$ & Age (years) & & & & Tribal $(N=100)$ & & Indigenous $(N=104)$ & & \\
\hline $\mathrm{t} 1.3$ & Mean & & & $26 \pm 7.24$ & & $28 \pm 7.37$ & & $25 \pm 6.85$ & \\
\hline $\mathrm{t} 1.4$ & $<20$ & 46 & 22.5 & & $16(16)$ & & $30(28.8)$ & & $p=0.041$ \\
\hline $\mathrm{t} 1.5$ & $20-34$ & 125 & 61.3 & & $62(62)$ & & $63(60.6)$ & & \\
\hline $\mathrm{t} 1.6$ & $\geq 35$ & 33 & 16.2 & & $22(22)$ & & $11(10.6)$ & & \\
\hline $\mathrm{t} 1.7$ & ANC no. of $v$ & & & & & & & & \\
\hline $\mathrm{t} 1.8$ & Mean & & & $7.9 \pm 2.2$ & & $8 \pm 2.3$ & & $7.6 \pm 2.1$ & \\
\hline $\mathrm{t} 1.9$ & $<8$ & 60 & 29.4 & & $24(24)$ & & $36(34.6)$ & & $p=0.103$ \\
\hline $\mathrm{t} 1.10$ & $\geq 8$ & 126 & 61.8 & & $65(65)$ & & $61(58.7)$ & & \\
\hline $\mathrm{t} 1.11$ & Missing & 18 & 8.8 & & $11(11.0)$ & & $7(6.7)$ & & \\
\hline $\mathrm{t} 1.12$ & Parity & & & & & & & & \\
\hline $\mathrm{t} 1.13$ & Mean & & & $2.7 \pm 2.2$ & & $3 \pm 2.5$ & & $2 \pm 1.8$ & \\
\hline $\mathrm{t} 1.14$ & $<1$ & 38 & 18.6 & & $14(14.0)$ & & $24(23.0)$ & & $p=0.178$ \\
\hline $\mathrm{t} 1.15$ & $\geq 1$ & 163 & 79.7 & & $84(84.0)$ & & $79(76.0)$ & & \\
\hline $\mathrm{t} 1.16$ & Missing & 3 & 1.5 & & $2(2.0)$ & & $1(1.0)$ & & \\
\hline
\end{tabular}

ANC Antenatal care, SD Standard deviation. 
Table 2 Birth outcomes of pregnant women receiving antenatal care in the interior of Suriname $(N=203)$

\begin{tabular}{|c|c|c|c|c|c|c|c|c|c|}
\hline t2.1 & Variable & $N=203$ & $(\%)$ & Mean \pm SD & & & & & $p$-value \\
\hline $\mathrm{t} 2.2$ & Birth weight (grams) & & & & Tribal $(N=99)$ & & Indigeno & $(N=104)$ & \\
\hline $\mathrm{t} 2.3$ & Mean & & & $3080 \pm 468$ & & $3093 \pm 515.3$ & & $3068 \pm 420.7$ & \\
\hline $\mathrm{t} 2.4$ & $<2500$ & 16 & 7.9 & & $8(50.0)$ & & $8(50.0)$ & & $p=0.385$ \\
\hline $\mathrm{t} 2.5$ & $\geq 2500$ & 182 & 89.6 & & $88(48.4)$ & & $94(51.6)$ & & \\
\hline $\mathrm{t} 2.6$ & Missing & 5 & 2.5 & & & & & & \\
\hline $\mathrm{t} 2.7$ & Preterm birth (weeks) & & & & & & & & \\
\hline $\mathrm{t} 2.8$ & Mean & & & $38.6 \pm 2.1$ & & $39 \pm 1.7$ & & $38 \pm 2.1$ & \\
\hline t2.9 & $<37$ & 30 & 14.8 & & $9(30.0)$ & & $21(70.0)$ & & $p=0.046^{*}$ \\
\hline t2.1 & $\geq 37$ & 167 & 82.2 & & $87(52.1)$ & & $80(47.9)$ & & \\
\hline $\mathrm{t} 2.1$ & Missing & 6 & 3.0 & & & & & & \\
\hline $\mathrm{t} 2.1$ & Apgar score & & & & & & & & \\
\hline t2.1 & $<7$ at 5 min & 5 & 2.5 & & & & & & \\
\hline $\mathrm{t} 2.1$ & $\geq 7$ at $5 \mathrm{~min}$ & 194 & 95.5 & & & & & & \\
\hline $\mathrm{t} 2.1$ & Missing & 4 & 2.0 & & & & & & \\
\hline t2.1 & Stillbirth & 5 & 2.5 & & 3 & & 2 & & \\
\hline
\end{tabular}

*Fishers's exact test

overestimated the prevalence of PTB [12]. We found associations between PTB and age, ethnicity, parity and ANC: PTB was more prevalent in young women $<20$ years and in Indigenous women.

$8 \%$ of the women in this sub-cohort had a newborn with low birth weight, lower than the incidence of LBW in the total cohort (13.1\%; Zijlmans et al., Cohort profile CCREOH MeKiTamara cohort study, BMJ Open, accepted for publication) and the country-wide rate of $14.7 \%$ [13], and comparable to most countries in Latin America and the Caribbean (Brazil 8.4\%, Venezuela 9.1\%, Dominican Republic 11.3\%) [13]. LBW prevalence was equally distributed among the Tribal and Indigenous participants. Maternal parity is a well-recognized predictor of infant birth weight, with nulliparous women being at greater risk of a child with LBW [14]. In our study one in three participants were primigravida, yet we found no association between parity and LBW. Lower birth weights among first born infants may be a direct consequence of physiological conditions associated with nulliparity, such as maternal pre-pregnancy weight and weight gain [15], these were not recorded in our study. Approximately $84 \%$ of the women in this study of which $65 \%$ had eight or more ANC visits, had a term birth with

Table 3 Maternal determinants associated with LBW and PTB $(N=203)$

\begin{tabular}{|c|c|c|c|c|c|c|c|c|c|}
\hline \multirow{2}{*}{$\begin{array}{l}\text { t3.1 } \\
\text { t3.2 }\end{array}$} & & \multicolumn{4}{|c|}{ Birth weight } & \multicolumn{4}{|c|}{ Gestational age } \\
\hline & & $<2500 \mathrm{~g}$ & $\geq 2500 \mathrm{~g}$ & $p$-value & OR(95\%Cl) & $<37$ wks & $\geq 37$ wks & $p$-value & OR(95\%Cl) \\
\hline $\mathrm{t} 3.3$ & Age & N (\%) & $N(\%)$ & & & $N(\%)$ & $N(\%)$ & & \\
\hline $\mathrm{t} 3.4$ & $<20 \mathrm{yr}$ & $4(8.7)$ & $42(91.3)$ & $0.416^{*}$ & & $14(31.1)$ & $31(68.9)$ & 0.005 & \\
\hline $\mathrm{t} 3.5$ & $20-34$ & $8(6.6)$ & 114(93.4) & & & $14(11.5)$ & $108(88.5)$ & & \\
\hline $\mathrm{t} 3.6$ & $\geq 35 \mathrm{yr}$ & $4(13.3)$ & $26(86.7)$ & & & $2(6.7)$ & $28(93.3)$ & & \\
\hline $\mathrm{t} 3.7$ & Ethnicity & & & & & & & & \\
\hline $\mathrm{t} 3.8$ & Tribal & $8(8.3)$ & 87 (91.7) & 0.899 & $1.07(0.38-2.97)$ & $9(9.4)$ & 87 (90.6) & 0.026 & $0.39(0.17-0.91)$ \\
\hline $\mathrm{t} 3.9$ & Indigenous & $8(7.8)$ & $94(92.2)$ & & & $21(20.8)$ & $80(79.2)$ & & \\
\hline $\mathrm{t} 3.10$ & ANC visits & & & & & & & & \\
\hline $\mathrm{t} 3.11$ & $<8$ & 2(3.6) & $54(96.4)$ & $0.350^{*}$ & & $18(32.1)$ & $38(67.9)$ & $<0.001$ & $5.49(2.33-12.93)$ \\
\hline $\mathrm{t} 3.12$ & $\geq 8$ & $11(8.7)$ & $115(91.3)$ & & & $10(7.9)$ & $116(92.1)$ & & \\
\hline $\mathrm{t} 3.13$ & Parity & & & & & & & & \\
\hline $\mathrm{t} 3.14$ & $\leq 1$ & $8(10.8)$ & $66(89.2)$ & 0.195 & $1.99(0.69-5.74)$ & 19 (26.0) & $54(74.0)$ & $<0.001$ & $3.94(1.72-9.05)$ \\
\hline t3.15 & $>1$ & $7(5.7)$ & $115(94.3)$ & & & $10(8.2)$ & $112(91.8)$ & & \\
\hline
\end{tabular}


birth weight above $2500 \mathrm{~g}$. Observations from a study conducted in Brazil [16] has shown that at least seven ANC visits were protective in LBW incidence. The greater the number of contacts with a healthcare provider, the greater the change of reducing risk factors or treating pregnancy complications with better results of birth outcomes [2].

Neither maternal age, parity nor ANC were associated with birth weight in our study. Several factors that were not included in the analyses of this sub-cohort study could be of influence such as maternal pre-pregnancy weight and weight gain during pregnancy [17], hypertension, and other well-known pre-existing maternal conditions. Women receiving antenatal care provided by MMPHCS are screened for these conditions and in case of early detection of abnormal findings women may be referred to the capital of Suriname. As a result, timely diagnosis and treatment interventions provided within the MMPHCS integrated primary health care program may help to adequately detect risk pregnancies, especially in these remote communities with its disadvantaged populations. MMPHCS refers approximately $60 \%$ of women with risk pregnancies annually [18]. Further studies are needed to assess the influence of risk factors for LBW and other adverse birth outcomes in women living in the interior of Suriname.

Two-thirds of our Indigenous study population was younger than 20 years compared to $35 \%$ of the Tribal women. Frequent ANC attendance is particularly important in pregnant adolescents aged $15-19$ as complications have been shown to be higher among these teenage girls [6]. In this risk group the mother and her offspring compete for nutrients as both are growing and developing [19]. Likewise, pregnant women 35 years and older are at risk for adverse perinatal birth outcomes due to pre-existing and probably undiagnosed diseases $[20,21]$ and pregnancy prevalence in this age group is increasing both in developed as developing countries over the last decade [22].

Parity was associated with preterm birth: women with first time pregnancies had a higher risk of preterm labor. Studies on the association between parity and preterm birth are inconclusive in their findings: in a metaanalyses no association was found [23], while others report multiparous women were more likely to deliver preterm $[24,25]$. Approximately $60 \%$ of the Indigenous group of participants had fewer than 8 ANC visits, indicating that less adherence to antenatal care may influence our PTB prevalence results.

In our study utilization of ANC services were 100\% covered for at least one visit during the pregnancy. In 2016, the World Health Organization (WHO) updated the Antenatal Care model with recommendation as follows: ANC should commence within the first 4 months of pregnancy and women should have at least eight ANC visits during the course of an uncomplicated pregnancy $[2,26]$. Although the number of eight antenatal care visits as part of the maternal and childcare portfolio provided by the MMPHCS for Tribal and Indigenous pregnant women in the tropical rainforest interior of Suriname meets the recommended WHO standards in terms of frequency of ANC visits, women had a significant rate of adverse birth outcomes. The incidence of less than 8 prenatal visits did vary by community, over half of the Indigenous women had less than 8 prenatal visits, this could be attributed to their way of living as these women are more engage in subsistence livelihood based on growing manioc and other root vegetables. The MMPHCS ANC guidelines cover all five WHO recommended components of ANC from obtaining the history of previous pregnancies to offering a home visit within 1 week after delivery. The authors recommend that improving the dissemination of essential information about ANC through the MMPHCS health care workers is critical to ensure that pregnant women living in the interior maximally benefit from these services. The health work force consists primarily of local villagers who receive a four-year health care training by the MMPHCS under supervision of the Surinamese Ministry of Health. These healthcare workers practice according to standardized guidelines and are supervised by MMPHCS physicians. In addition, community education programs regarding for example how to correctly determine the last menstruation period should be emphasized. In addition, expansion of ANC services is recommended including introduction of ultrasounds for more accurately estimating gestational age.

Women living in remote interior communities in Suriname, where mercury is abundantly used in artisanal and small-scale goldmining activities, are known to have high concentrations of mercury in hair [23]. These high mercury concentrations can largely be attributed to the consumption of mercury contaminated fish [24]. In a recent study we conducted we found no differences in birth outcomes associated with downstream proximity to gold mining [25].

One of the strengths of our study is that all pregnant women in our study population received a standardized package of ANC care which covered all the recommendations indicated by WHO. In addition, the data were abstracted from accurately documented medical records. This is also the first study to evaluate the impact of ANC utilization with an almost $100 \%$ adherence and frequency of adverse birth outcomes in the interior of Suriname.

The study included some limitations: we did not assess the quality and content of ANC as this may influence 
the ANC across the different MMPHCS health facilities; secondly, we did not examine the mother's history of PTB and LBW; mothers with previous PTB or LBW are more likely to have babies with LBW [27]. Also, gestational age was not calculated by ultrasound but instead obtained using the LMP date, therefore the exact gestational age could not be determined. Finally, in Suriname, national data on characteristics of the pregnant population, pregnancy and delivery are not readily available, for example data on body mass index, hypertension, diabetes, pre-pregnancy weight and gestational vascular disease are all correlated to perinatal outcome hampering assessment of potential relevant risk factors.

\section{Conclusion}

Despite the high attendance of ANC, over one fifth of women living in the interior of Suriname that received antenatal care from the Medical Mission Primary Health Care Suriname had adverse birth outcomes, particularly preterm birth and low birth weight. Younger nulliparous Indigenous women with less than the recommended 8 ANC visits were particularly at risk for PTB. The high rate of adverse birth outcomes highlights the need for further research to better assess the factors influencing perinatal outcomes and also strategies to put in place to improve perinatal outcomes. Exposure assessment of this sub-cohort and neurodevelopment testing of their children is ongoing and will further inform other potential adverse health effects associated with environmental exposures. A client satisfaction survey is recommended to evaluate the ANC services provided by the MMPHCS.

\section{Abbreviations}

ANC: Antenatal Care; AS: Apgar Score; CCREOH: Caribbean Consortium of Environmental and Occupational Health; Hg: Mercury; LBW: Low Birth Weight; LMP: Last Menstrual Period; MMPHCS: Medical Mission Primary Health Care Suriname; NGO: Non-Governmental Organization; NMR: Neonatal Mortality Rate; PTB: Preterm Birth; SD: Standard Deviation; WHO: World Health Organization

\section{Acknowledgements}

We thank all participants and acknowledge the key role of the Medical Mission Primary Health Care Suriname healthcare assistants in assisting in the recruitment of the participants. We thank Arioene Vreedzaam for his technical assistance in making the map of Suriname. This study received financial support of the Fogarty International Center of the National Institutes of Health under Award Numbers: U01TW010087 and U2RTW010104

\section{Declarations}

None to declare.

\section{Authors' contributions}

GB wrote the paper, conducted the data analysis, interpreted the analyses and processed feedback from co-authors; BJ assisted with the data analysis; EvE reviewed and edited the paper; AS reviewed the overall statistical plan, assisted with analyses; AHM edited and reviewed the paper; HC: edited and reviewed the paper; LS laid out study design, reviewed and edited the paper; ML laid out study design, reviewed and edited the paper; WZ: laid out study design, reviewed and edited the paper. All authors read and approved the final manuscript.

\section{Funding}

Research reported in this publication was supported by the Fogarty International Center of the National Institutes of Health under Award Numbers: U01TW010087 and U2RTW010104. The content is solely the responsibility of the authors and does not necessarily represent the official views of the National Institutes of Health. The National Institutes of Health played no role in the design of the study and collection, analysis, and interpretation of data and in writing the manuscript.

\section{Availability of data and materials}

The datasets generated and/or analyzed during the current study are not publicly available due to ongoing data analysis beyond what is currently included in this study but are available from the corresponding author on reasonable request.

\section{Ethics approval and consent to participate}

This study was approved by the Institutional Review Boards (IRB) of both Tulane University and the Medical Ethical Commission of Suriname's Ministry of Health (VG 023-14). Potential participants received documentation describing all aspects of the MeKiTamara study (e.g. content, benefits, risks, incentives). All women included in this study $(n=204)$ provided written informed consent. Assent was obtained from participants 16 or 17 years of age.

\section{Consent for publication}

Not applicable.

\section{Competing interests}

The authors declare that they have no competing interests.

\section{Author details}

${ }^{1}$ Medical Mission Primary Health Care Suriname, Paramaribo, Suriname. ${ }^{2}$ Faculty of Medical Sciences, Anton de Kom University of Suriname, Paramaribo, Suriname. ${ }^{3}$ Tulane University School of Public Health and Tropical Medicine, New Orleans, USA. ${ }^{4}$ Foundation for Perinatal Interventions and Research in Suriname (Perisur), Paramaribo, Suriname. ${ }^{5}$ Scientific Research Center Suriname / Academic Hospital Paramaribo, Paramaribo, Suriname.

Received: 2 May 2020 Accepted: 27 October 2020

Published online: 11 November 2020

\section{References}

1. Kuhnt J, Vollmer S. Antenatal care services and its implications for vital and health outcomes of children: evidence from 193 surveys in 69 low-income and middle-income countries. BMJ Open. 2017;7(11):e017122. https://doi. org/10.1136/bmjopen-2017-017122.

2. World Health Organization, editor. WHO recommendations on antenatal care for a positive pregnancy experience. Geneva: World Health Organization; 2016.

3. Khammany P, Yoshida Y, Sarker MAB, Touy C, Reyer JA, Hamajima N. Delivery care satisfaction at government hospitals in xiengkhuang province under the maternal and child health strategy in lao pdr. Nagoya J Med Sci. 2015;77(1-2):69-79.

4. Miranda $A E$, et al. Factors associated with prenatal care and seeking assistance in public hospitals in Vitoria, Espirito Santo, Brazil. Women HIth. 2010:50(3):229-40. https://doi.org/10.1080/03630242.2010.480904.

5. "UNICEF For Every CHILD 2018." https://data.unicef.org/country/sur/.

6. "The World Bank 2018." https://data.worldbank.org/country/suriname?view= chart.

7. "General Bureau of Statistics Suriname 2015-2018." https://statisticssuriname.org/en/population-statistics-2/.

8. "Suriname- Multiple indicatot Cluster Survey 2018." Oct. 18, 2019, [Online]. Available: https://datacatalog.worldbank.org/dataset/suriname-multipleindicator-cluster-survey-2018.

9. Lichtveld MY, Zijlmans C, Mans DRA, Hawkins WB. GEOHealth - The Caribbean Consortium for Research in Environmental and Occupational Health: Environmental Health Science Research Training in Suriname. Ann Global Health. 2017;83(1):90. https://doi.org/10.1016/j.aogh.2017.03.202.

10. "World Health Organization Preterm Birth," Feb. 19, 2018. https://www.who. int/news-room/fact-sheets/detail/preterm-birth. 
11. da Silva AAM, et al. Young maternal age and preterm birth. Paediatr Perinat Epidemiol. 2003;17(4):332-9. https://doi.org/10.1046/j.1365-3016.2003.00515.X

12. Ambrose CS, Caspard H, Rizzo C, Stepka EC, Keenan G. Standard methods based on last menstrual period dates misclassify and overestimate US preterm births. J Perinatol. 2015;35(6):411-4. https://doi. org/10.1038/jp.2015.25.

13. "UNICEF 2019." https://data.unicef.org/country/sur/.

14. Khan A, Nasrullah FD, Jaleel R. Frequency and risk factors of low birth weight in term pregnancy. Pak J Med Sci. 1969;32(1). https://doi.org/10. 12669/pjms.321.8120.

15. Hinkle SN, et al. The association between parity and Birthweight in a longitudinal consecutive pregnancy cohort: parity and birthweight in consecutive pregnancies. Paediatr Perinat Epidemiol. 2014;28(2):106-15. https://doi.org/10.1111/ppe.12099.

16. Branco da Fonseca CR, Strufaldi MWL, de Carvalho LR, Puccini RF. Adequacy of antenatal care and its relationship with low birth weight in Botucatu, São Paulo, Brazil: a case-control study. BMC Pregnancy Childbirth. 2014;14(1):255. https://doi.org/10.1186/1471-2393-14-255.

17. Asefa F, Cummins A, Dessie Y, Hayen A, Foureur M. Gestational weight gain and its effect on birth outcomes in sub-Saharan Africa: Systematic review and meta-analysis. PLoS One. 2020;15(4):e0231889. https://doi.org/10.1371/ journal.pone.0231889.

18. "Medische Zending PHCS Jaarverslag 2016," Medische Zending Primary Health Care Suriname, Annual report. [Online]. Available: http://www. medischezending.sr/wp-content/uploads/2018/01/Laatste-versiejaarverslag-2016.pdf.

19. Scholl TO, Hediger ML, Ances IG. Maternal growth during pregnancy and decreased infant birth weight. Am J Clin Nutr. 1990;51(5):790-3. https://doi. org/10.1093/ajcn/51.5.790.

20. Heffner LJ. Advanced maternal age — how old is too old? N Engl J Med. 2004;351(19):1927-9. https://doi.org/10.1056/NEJMp048087.

21. Stein Z. The risks of having children in later life. BMJ. 2000;320(7251):1681-2. https://doi.org/10.1136/bmj.320.7251.1681.

22. Montan S. Increased risk in the elderly parturient. Curr Opin Obstet Gynecol. 2007;19(2):110-2. https://doi.org/10.1097/GCO.0b013e3280825603.

23. Ouboter PE, Landburg GA, Quik JHM, Mol JHA, van der Lugt F. Mercury levels in pristine and gold mining impacted aquatic ecosystems of Suriname, South America. AMBIO. 2012;41(8):873-82. https://doi.org/10. 1007/s13280-012-0299-9.

24. Wickliffe JK, et al. Exposure to total and methylmercury among pregnant women in Suriname: sources and public health implications. J Expo Sci Environ Epidemiol. 2020. https://doi.org/10.1038/s41370-020-0233-3.

25. Baldewsingh GK, et al. Prenatal Mercury Exposure in Pregnant Women from Suriname's Interior and Its Effects on Birth Outcomes. IJERPH. 2020;17(11): 4032. https://doi.org/10.3390/ijerph17114032.

26. J. Villar and P. Bergsjo, "WHO antenatal care randomized trial: manual for the implementation of the new model." World Health Organization, 2002. Available: https://apps.who.int/iris/handle/10665/42513.

27. Su D, et al. Birth history as a predictor of adverse birth outcomes: evidence from state vital statistics data. Prev Med Rep. 2018;11:63-8. https://doi.org/ 10.1016/j.pmedr.2018.05.011.

\section{Publisher's Note}

Springer Nature remains neutral with regard to jurisdictional claims in published maps and institutional affiliations.

Ready to submit your research? Choose BMC and benefit from:

- fast, convenient online submission

- thorough peer review by experienced researchers in your field

- rapid publication on acceptance

- support for research data, including large and complex data types

- gold Open Access which fosters wider collaboration and increased citations

- maximum visibility for your research: over $100 \mathrm{M}$ website views per year

At BMC, research is always in progress.

Learn more biomedcentral.com/submissions 